\title{
Research on Sustainable Development of Chinese Human Resources and Natural Resources
}

\author{
BAI Ning \\ Shaanxi Normal University \\ International Business School \\ Xi'an, China \\ 983779750@qq.com
}

\begin{abstract}
The sustainable development of resources includes two aspects, namely human resources and natural resources. Based on China's situation and the view of resources, this paper analyzes the existing problems and maneuverability of the sustainable development strategy of China's resources from two aspects of time and policy, and puts forward the countermeasures to promote the sustainable development of human resources and natural resources.
\end{abstract}

Keywords-Human resources; Natural resources; Sustainable development; Strategy

\section{INTRODUCTION}

"Sustainable development" has been widely accepted in today's society, and has become a major concern of governments around the world. China must take the road of sustainable development, which is an inevitable choice. In order to realize the sustainable development of resources, the sustainable development of natural resources, economic resources and the sustainable development of human resources should go hand in hand with the "two feet walking" at the same time. Twenty-first Century is a period of great economic development in the world, but mankind has paid a heavy price for it. Environmental pollution, ecological imbalance and resource exhaustion have been exhausted. When the world faces serious economic, social, resource and environmental problems, human beings are compelled to reflect on their own production and living behavior under the hardships of reality and future. The sustainable development is a new concept of development in this context. It has aroused widespread concern in the world, and is now widely and deeply integrated into various development planning strategies of the world.

\section{THE CORE OF THE THEORY OF SUSTAINABLE DEVELOPMENT}

The practice has proved that the core of the theory of sustainable development should be closely related to the two basic lines, to seek the balance between human and nature, to seek the harmonious development of man and nature, and to construct the rational relationship between man and nature, and to closely link the development of human, the consumption of resources, the degradation of the environment and the coordination of the ecology. This relationship embodies the path of harmony and cooperation between man and nature, and efforts to realize the coordination of relations between people and people. Through the guarantee of the system, the guidance of the public opinion, the ethical norms, the moral appeal, the rule of law, the justice of the society and the edification of the culture, the effective organization of human activities is basically reached between people and people. The harmony and fairness of the relationship, whether it is China's sustainable development or the global sustainable development such a grand goal, we should pay attention to the effective coordination of the relationship between people and nature, is the material basis for ensuring sustainable development, and the guarantee of the harmonious relationship between people and the realization of sustainable development.

\section{REALIZATION ANALYSIS OF SUSTAINABLE DEVELOPMENT}

In terms of time, the state hopes to achieve zero growth in the natural growth rate of the population by 2030 ; by 2040 , zero growth in the rate of energy and resource consumption is achieved; by 2050, a zero increase in the rate of degradation of the ecological environment is basically achieved. Some scholars believe that any country can achieve sustainable development through the steps of "three zero growth". First, the zero growth rate of the natural population growth rate, that is, the basic balance between birth rate and death rate, remains to be accomplished in China. Second, it is possible to achieve zero growth in the rate of resources and energy consumption only after the basic balance of the population, which is only possible after the establishment of a conservation oriented society and a new road of industrialization. Thereafter, the rate of degradation of the ecological environment is likely to achieve zero growth. The author speculates that, as the largest developing country in the world with the largest population in the world, it is expected that at least 50 years will be needed to achieve the strategic goal of sustainable development in order to successfully complete the "three zero growth" step.

In terms of policy, the policy of sustainable development is a guarantee for the implementation of the sustainable development strategy. It is the product of the expansion and integration of environmental policies to economic and social development policies. The government environmental departments of some countries such as Europe, the United States, Japan and other countries cooperate with the economic sector and extensively invite all walks of life to take part in the 
formulation of a comprehensive system. The long-term environmental policy planning to achieve the integration of environmental and economic policies, China also has some progress in this respect, and there are some policy options. But how to formulate and implement the policy of sustainable development in the economic and social development policy is still a serious social issue. The policy of sustainable development in China is mainly embodied in three points: (1) controlling population growth, improving the quality of population, making use of resources rationally, insisting on the equal importance of development and economize, strengthening pollution control and protecting the ecological environment.

\section{ANALysis OF SUSTAINABLE DEVELOPMENT OF RESOURCES}

\section{A. Analysis of the ways of sustainable development of human resources}

The problem of the sustainable development of human resources in China shows in the following aspects: (L) the unbalanced development of population, manpower and talent; (2) the lack of human resources, the number of labor force and the quality of labor; (3) the imbalance of human resources structure and the existence of faults; (4) the lack of human resources and waste; (5) talent There is a lack of organic integration between the 3 links of selection, education and use. The people are more and more aware that our country has a large population and a lack of resources. The economic development can no longer take the traditional, extensive and large scale material resources. At present, it has become a consensus to improve the quality of human resources and the high technology content of production so as to establish a new model of economic growth. To this end, the measures to promote sustainable development of human resources are as follows:

\section{1) Improve the quality of population}

To continue to carry out the basic national policy of "controlling the population and improving the quality of the population", the large population has both advantages and disadvantages for China. Fortunately, according to the famous economist, a large population has a large population gene pool. We should continue to carry out the basic national policy of our country. It is necessary to maintain an appropriate population size, excellent population quality and reasonable population structure to promote the coordinated development of human resources and economy, society and environment. Promoting the pace of sustainable development of human resources.

\section{2) Energetically Conduct the development of educational} undertakings

Put the development of education in the primary position of economic development and deepen the reform of educational system. Education is a big industry. It is the way to produce, disseminate the latest knowledge and cultivate creative talents. It is a large system of national basic education, social vocational education, professional knowledge education, and lifelong education for all. We should put adult education and general education on the same important position, train staff system and law to adjust and optimize the structure of education, reform the content of teaching, promote the connection between higher education and enterprises, and expand the stage of school education into lifelong education in order to create high-quality talents.

3) Establish laws, regulations and policy guarantee systems for human resources development.

Through the establishment and maintenance of the legitimate rights and interests of the workers to accept training, the protection of the rights of independent employers and workers to choose their own business, and other relevant supporting laws, regulations and policies. For example, human resource allocation system, development and use of risk bearing system, human resources development into the legal track, to build a reasonable mechanism for intellectual investment and return.

\section{B. Analysis of the way of sustainable development of natural resources}

1) Coordination of the relationship between resources, environment and development

Resources are the foundation of social and economic development. Environment is the external condition for human survival and social economic development. In different stages of social and economic development, the status and function of natural resources and natural resources, social resources (artificial capital) are different. In the period of natural economy, the development of resources is not large and the quantity is not much. The social and economic activities of human beings depend on the nature, and the contradiction between the resource environment and the social economy is not very prominent. With the increase of social productive forces, the proportion of social resources (artificial capital) has gradually increased, the ability of people to develop natural resources is increasing, and environmental pollution is becoming more and more serious. Human social economic activities and nature are incongruous to contradictions and intensification. Since the second half of the twentieth Century, the contradiction between resources, environment, population and socio-economic development has become a major global hot issue. Therefore, the formulation of resources and environment policy is based on the coordination of resources, environment, population and development. At different stages of social development in different countries or regions, there are different modes of dealing with the relationship between resources, environment, population and development. Low income countries and regions focus on developing economy, solving the problem of food and clothing, high income countries and regions, and paying more attention to the 
improvement of the ecological environment that people depend on for survival. Therefore, their respective resources and environmental policies are different.

2) Realize the sustainable development of resources, environment and economy

China's economy is developing rapidly and moving towards the second strategic goals. At the moment, we are building a well-off society in an all-round way. By the middle of this century, the overall realization of modernization and the per capita GNP will reach the level of the middle developed countries. To achieve these goals, the government regards the sustained development of the economy and society as the basic national policy. The sustainable utilization of natural resources and the virtuous circle of the ecological environment are the basic conditions and material guarantee for the implementation of the basic national policy. Therefore, the overall goal of formulating resources and environmental policies is sustainable utilization of natural resources, a virtuous cycle of ecological environment, and the sustained development of social economy. Sustainable utilization of resources is a way of resource utilization to meet the needs of contemporary people without damaging the natural material foundation of future generations to meet their needs. A rational resource utilization mode with reasonable allocation of resources among generations, suitable allocation among industries, and consideration of economic, social and environmental benefits. The virtuous cycle of the ecological environment is to reduce the pollution of the waste to the environment by rational utilization of resources and the reuse of two resources to reduce the pollution of the waste to the environment, to make the environment self purification, to effectively protect and improve the regeneration capacity of the ecosystem, and to maintain a benign cycle of the ecological environment.

\section{3) Construction of the rule of law system}

As the main basis for the formulation of China's sustainable development policy, the basic national policy of sustainable development, the socialist market economy system, the objective requirement for the realization of the optimal allocation of resources, the development and utilization of resources and the protection of the ecological environment should be considered as the main basis for the formulation of China's sustainable development policy. The principle of laying equal stress on both sides and taking into account the principles of state, collective and individual interests.

In the process of social and economic development at home and abroad, in the process of industrialization and urbanization, we should deal with the experience and lessons of the major problems, such as population growth, economic development, social progress and the rational exploitation and utilization of resources and environmental protection, and learn foreign effective policies, regulations and management methods, and summarize the rich practice of our country for a long time. We should improve and rationale the resources and environment policies for China's sustainable development. To integrate resources and environmental management into the system of socialist market economy, take the track of legal management, and gradually formulate and implement a policy system that combines economic means and laws and means to change government direct control to play the role of market allocation of resources. The government standardizing the market of resources and environmental industry through relevant laws, regulations and policies, and managing resources and environment through market mechanism to make it in the direction of increasing the value of natural resources. At the same time, we must use essential direct control measures to control resource destruction and environmental degradation. To establish and improve the policy system of resources and environment under the market economy system so as to integrate all kinds of policy areas between resources, resources and environment, so that different management departments should apply unified economic means to manage resources and environment, and protect the resources and the environment, and move from the end to the whole process and the whole process of punishment. Control.

\section{SUMMARY}

Fundamentally, China has not completely changed the "high investment, high consumption, high emission, incoordination, difficult circulation, low efficiency" of extensive economic growth mode. Because of the extensive growth mode, the cost of resources and environment is too high in the rapid economic growth, which aggravates the pressure of the shortage of energy and resources, which makes the contradiction and situation of sustainable development quite prominent and severe. The key is to set up a scientific concept of development, promote the development model of circular economy, and take a new industrialization road with high scientific and technological content, good economic benefit, less resource utilization, low environmental pollution and full use of human resources. On the one hand, we should study, develop and popularize new energy and new materials, widely adopt the pollution control technology and ecological destruction recovery technology, including low investment and high efficiency wastewater treatment technology, the comprehensive treatment technology of urban air pollution, the harmless treatment technology of solid waste and so on. On the other hand, we should vigorously develop advanced productive forces. Carry out strategic adjustment of economic structure, eliminate backward technology and equipment, shut down and ban enterprises with serious pollution, and change the development mode of "resource production pollution emission" in traditional industry as the circular development mode of "resource production renewable resources", and promote the characteristics of clean production, recycling economy and ecological economy. The rapid development of green productivity makes it an important part of the advanced productive forces and the best combination of environmental protection. China's road to sustainable development not only provides experience for the following billions of developing countries, but also makes more contributions to the sustainable development of the world. The rise of new developing countries has changed the world economic and political structure, and China is playing an increasingly important role in the world. 


\section{REFERENCE}

[1] Zhang Xiaoling. Sustainable development theory: concept evolution, dimension and Prospect $[\mathrm{J}]$. Bulletin of Chinese Academy of Sciences, 2018, 33(01):10-19.

[2] Lv Yonglong, Wang Yichao, Yuan Jingjing, He Guizhen. Reflections on China's implementation of the goal of sustainable development [J]. China's population, resources and environment, 2018, 28(01):1-9.

[3] Shally Wang. Sustainable development goals and PPP standards in the perspective of Globalization: China's choice [J]. Reform, 2016(02):2034.

[4] Miao toughen, Zhou Fuqiu, Hu Xiulian, Feng Shengbo, Wu Shu, Jia Ru.Study on comprehensive evaluation of China's energy sustainable development [J]. Chinese Soft Science, 2013(04):17-25.

[5] Toshiyuki Sueyoshi, Yan Yuan. Measuring energy usage and sustainability development in Asian nations by DEA intermediate approach [J]. Journal of Economic Structures, 2018, 7(1)

[6] Qibin Zhang, Depeng Yue, Minzhe Fang, Qiang Yu, Yuan Huang, Kai $\mathrm{Su}$, Huan Ma, Yuhang Wang. Study on sustainability of land resources in Dengkou County based on em. 